Article

\title{
Constructivism-Based Methodology for Teaching Artificial Intelligence Topics Focused on Sustainable Development
}

\author{
Georgina Mota-Valtierra ${ }^{\dagger}, J^{\prime}$ uvenal Rodríguez-Reséndiz ${ }^{*}+{ }^{\dagger}$ and Gilberto Herrera-Ruiz ${ }^{\dagger}$ \\ Facultad de Ingeniería, Universidad Autónoma de Querétaro, Querétaro 76010, Mexico \\ * Correspondence: juvenal@uaq.edu.mx; Tel.: +52-442-192-12-00 \\ + These authors contributed equally to this work.
}

Received: 18 July 2019; Accepted: 20 August 2019; Published: 26 August 2019

check for updates

\begin{abstract}
This article proposes the creation of a course based on a series of practical sessions, where the students have to develop their practical knowledge about artificial intelligence techniques, specifically multilayer perceptron. The novelty of this paper is based on the constructivism methodology regarding artificial intelligence and sustainable development. Moreover, it can be implemented in different majors because of the flexibility in certain aspects. It is oriented to evaluate skills in the broad education necessary to understand the impact of engineering solutions in a global, economic, environmental, and societal context. The proposal helps the students to turn theoretical concepts into more tangible objects where they can build their knowledge by programming their implementations in software. Then, programming codes for practicing the neural networks theory, finite impulse response, empirical mode decomposition and discrete wavelet transform are achieved to compare percentage classification between different techniques. Also, it measures the interaction between the student and the theoretical mathematics of artificial intelligence. The continuous evaluations at the end of the practical sessions corroborate the increase in the knowledge of the students. A study based on rubrics illustrates an increase in the average grade obtained by the students in the elaboration of each practice. Finally, a senior project is carried out by taking into account sustainable development issues and the usage of tools of artificial intelligence.
\end{abstract}

Keywords: constructive learning; sustainable development; undergraduate education; multidisciplinary project; signal processing; artificial intelligence

\section{Introduction}

The generation of new technologies have changed the teaching methods and the knowledge with which young people have to be approached, and in this changing world, artificial intelligence (AI) is one of them. It can often be seen that these techniques are applied to solve real problems from daily life and professional work. Due to the increase of information available on the internet, the manual classification of content is becoming an increasingly complex task, and it is here that the AI has taken on high relevance to process and understand data autonomously, for example in the classification of music or visual content according to the genres and personal tastes of each user. Another application where AI is enabling breakthroughs is in autonomous vehicle navigation, where large amounts of data obtained by sensors and cameras serve as training data for different $\mathrm{AI}$ approaches [1-3]. It is for this reason that teaching undergraduate students $\mathrm{AI}$ is fundamental in different areas of engineering. However, one of the main challenges is to be able to transmit this knowledge to the students in a didactic way. Students are ready and equipped to identify, address, and solve the issues of the contemporary world. They require a global perspective to streamline and coordinate solutions. Then, they can develop their skills 
and use the techniques and engineering tools necessary for the practice [4]. It is important to consider authors such as Piaget and Vygotsky [5,6] for their theories in the field of education to determine the appropriate methodology although it is true that their theories differ in some points there are others of the profound agreement. For example, both establish that the physical world and the sociocultural environment have a significant influence on the learning process, and considering what has been said by them is that it was decided to teach this course to students belonging to different public institutions at a higher level. All of those have administrative and academic processes and seeks to determine if these are factors that can influence the process and learning. This is not considered in previous works as [5-9].

On the other hand, Piaget and Vygotsky also establish that the learning process is facilitated by practice and lived experiences because it allows the individual to relate new knowledge with previous knowledge [10-14]. Besides, when learning is done interactively, it can contribute to the improvement in the acquisition of technical knowledge; communication skills such as reading, understanding, and research of technical topics. Then, it is a way to promote interactive learning is through the use of practical laboratory sessions, which allows the student to put into practice the knowledge obtained in class, covering different types of learning [15].

The theory of Piaget states that "Thought develops at the moment that an idea is generated in the mind to follow a process until reaching the maturity of the idea that is the thought." According to this idea is that the practices are designed with a sequence that goes guiding the student step by step on the theory that involves an Multilayer Perceptron (MLP), its application and how it can relate to knowledge acquired in previous courses [5].

For this reason, it was decided to develop the practical sessions to facilitate the learning-teaching process. In a globalized world, multidisciplinarity has become very important, since it is difficult to imagine that the teaching-learning process can occur in isolation. The benefits of multidisciplinarity have been mentioned by authors such as [16-24]. In this approach has been developed a multidisciplinary course. The statistics presented are collected by taking a laboratory course for AI topics in multidisciplinary undergraduate programs into account three different majors in Universities of México, which include Biomedical, Electronics, and Communications, and Mechatronic Engineering.

Piaget establishes that the cognitive process is divided into different stages. Nevertheless, these stages are universal [13]. Considering the previous statement it was looked for that the participants in the course had similar ages and semesters. The period of the implementation of this workshop is in the seventh-semester biomedical major, ninth semester mechatronics, and ninth semester electronics and communication. According to Vygotsky, the learning process depends on the quality of interaction. Therefore, the instructor teaches the course to attempt to standardize as much as possible the work environment and the teaching method.

In recent years educational institutions have needed specialized organizations to accredit their teaching processes, to ensure highly qualified graduates for working life. Therefore, it is necessary to design teaching and learning strategies that comply with specific guidelines. At the time of designing this practical it was considered that the educational institutions that participated are accredited before organisms such as Interinstitutional Committees for the Evaluation of Higher Education C. A. (CIEES), Accreditation Board for Engineering and Technology Inc. (ABET) and Accreditation Council for Engineering Education C. A. (CACEI), just to mention a few. Thus, these practical sessions meet the criteria established by these accrediting institutions. Then, one of the purposes of this paper is to assess the (C) outcome of ABET [25], which mentions that students develop the skill "The broad education necessary to understand the impact of engineering solutions in a global, economic, environmental, and societal context." As a result, by using AI tools, a sustainable development project is achieved by the students under the supervision of the teacher. Sustainable development has been selected as a topic of interest for the aim of certain engineering courses due to the concern of contemporary issues [26]. Finally, it is worth mentioning that this course was offered in three different modalities, a semester course of $4 \mathrm{~h}$ per week, a summer course $12 \mathrm{~h}$ a week, and finally an intensive course of $30 \mathrm{~h}$ per week. 
In Section 2 we explain the theoretical concepts of the topics covered in the proposed method. Section 3 presents a course description with theoretical and practical sessions. Section 4 illustrates the student evaluation rubrics. Sections 5 and 6 carry out the discussion and conclusions, respectively.

\section{Theory Topics Covered in the Course}

The following section briefly describes the theory of signal processing techniques used by students in the development of practices, as well as the theory of multilayer perceptron.

Signal processing is fundamental in most current systems. The rapid advance in computer science as well as hardware, has allowed the implementation of several ideas developed some centuries ago, for example, the Fourier transform (FT). Unlike synthetic signals, where the signal-to-noise ratio is a controlled parameter, in real signals used in present work such as brain activity and motor vibrations, usually present a low signal-to-noise ratio, which limits the learning process of a neural network. Furthermore, the type of signal will determine the processing that can be applied. The processing methods chosen in this work are in both, time and frequency domain, selecting those that, according to the literature, are commonly used in the analysis of mentioned signals [27].

\subsection{Finite Impulse Response}

Finite impulse response (FIR) is a type of filter whose response to an impulse input signal has a finite number of terms other than zero. The filter considers obtaining the output of the current and previous inputs using a discrete convolution of the input signal $x(n)$ with a set of filter coefficients $b_{k}$. In general, the FIR system is written with the difference equation and applying the $\mathrm{Z}$ transform in Equation (2) is obtained [28].

$$
Y(n)=\sum_{k=0}^{M-1} b_{k} X_{n-k}
$$

From 1 the transfer function of the FIR structure is obtained:

$$
H(z)=\sum_{k=0}^{M-1} b_{k} Z^{-k}
$$

From 2, it is clear that the function only contains zeros because the poles are located at the origin, and for this reason, a FIR type filter is always stable. The current output of the system is the weighted sum of the present and past inputs. It is not recursive since it does not depend on the past results as it happens in the case of the infinite impulse response (IIR) structure so that in the absence of feedback, the rounding and truncation errors that are present in any structure of this type are largely avoided.

\subsection{Wavelet Transform}

The Wavelet Transform (WT) is a technique used in signal processing, because it is possible to analyze in the frequency domain maintaining the temporal aspect. In addition, it provides the multiresolution approach with dilated windows according to the frequencies [29].

$$
\psi_{j, k}(t)=2^{-j / 2} \psi\left(2^{-j} t-k\right),
$$

where $j$ and $k$ are integers that scaled and displaced the prototype function, called the mother wavelet. Discrete Wavelet Transform (DWT) is a signal obtained through Wavelet function discretized, and is defined as follows:

$$
c_{j, k}(t)=\int f(t) \psi_{j, k}^{*}(t) d t,
$$

where $c_{j, k}$ is the Wavelet coefficient. The DWT calculates the Wavelet coefficients $c_{j, k}$ and $d_{j, k}$ for $=1, \ldots, j$, using (5) and (6)

$$
c_{j, k}=\sum_{n} x[n] g_{i}\left[n-2^{j} k\right]
$$




$$
d_{j, k}=\sum_{n} x[n] h_{i}\left[n-2^{j} k\right],
$$

where $x[n]$ is a discrete sequence, $h_{j}\left[n-2^{j} k\right]$ is called discrete wavelet and $g_{j}\left[n-2^{j} k\right]$ is called scaling sequence. In the $j$-th resolution, $c_{j, k}$ and $d_{j, k}$ represent the approximation and detail coefficients. At each resolution $j>0$, the scaling coefficients and the wavelet coefficients are obtained with (7) and (8)

$$
\begin{aligned}
c_{j+1, k} & =\sum_{n} g[n-2 k] d_{j, k} \\
d_{j+1, k} & =\sum_{n} h[n-2 k] d_{j, k} .
\end{aligned}
$$

\subsection{Empirical Mode Decomposition}

Empirical Mode Decomposition (EMD) is part of the proposed Hilbert-Huang transform (HHT) [22]. The EMD decomposes any data set into intrinsic mode functions (IMF) that are not analytically established and instead are determined by a single series analyzed. An IMF meets the following two conditions:

- It contains the same number of crosses by zero and IMF which are the sum of maximum and minimum or different by at least one.

- In an IMF, the average value of the envelope defined by the local maximum and that defined by the local minimum is zero.

The algorithm proposed in [30], determines the local minimum and maximum points of the original signal which joins by means of lines. The signal obtained by the maximum is subtracted from the signal formed by the local minimum, and the signal resulting from the subtraction of local maximum and minimum is subtracted from the original signal. The calculated mean value is subtracted from the initial series. This process is performed repetitively until the signal resulting from the subtraction of local maximum and minimum does not contain more than two extremes. This technique is not based on strict mathematical calculations. It is an empirical process.

\subsection{Multilayer Perceptron}

$\mathrm{AI}$ is a set of techniques usually in biological or evolutionary processes [31,32], specifically artificial neural networks (ANN) are in the process of learning or biological processes that are performed in the human brain. A perceptron is one of the first models of ANNs, which is a linear classifier. MLP is formed by the interconnection of individual perceptron with one or more hidden layers between the inputs and outputs vectors. Each neuron performs a linear combination of inputs that are multiplied by initial random weights. This calculation is passed through an activation function, generally with sigmoidal form, where the outputs of a layer are the inputs vectors in the next layer. The hidden layers allow solving nonlinear problems that a single perceptron cannot [33]. Figure 1 shows a basic MLP topology with four inputs, one hidden layer, and three outputs. 


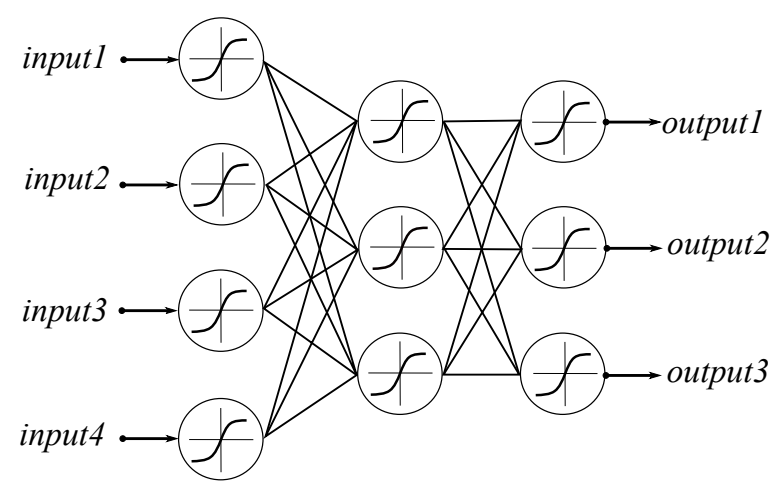

Figure 1. The basic layer of an Multilayer Perceptron (MLP), with an input layer, a hidden layer, and an output layer.

The activation of $\mathrm{j}-\mathrm{th}$ neuron in the k-th layer is defined by Equation (9).

$$
u_{j}^{k}=f_{i}\left(\sum w_{i j} u_{i}^{(k-1)}\right)
$$

where, $f_{j}$ is the activation function, $w_{j i}$ is the weight between connection, and $u_{i}^{(k-1)}$ is the output value of a neuron in the previous layer. The training algorithm consists of changing the initial weights according to the error between the desired and calculated output. This concept is described below.

$$
w(t+1)=w(t)+\eta(d(t)-y(t)) x(t)
$$

where $w$ is the weight, $\eta$ is the learning rate $d(t)$ the desired output, and $y(t)$ the calculated output. In MLP this expression is generalized and error in the hidden layer is calculated by the backpropagation algorithm [34]. MLP is easy to implement, but the training is complex because it is possible that the given solution is not the global minimum. The choice of adequate network parameters such as the number of hidden layers or the number of neurons in each layer is a challenge and still a heuristic task [31,32].

\section{Course Description}

The course is composed of both theoretical and practical sessions. The theoretical background used for the course includes MLP [33,35,36], heuristic task [34], DWT [29], FIR [28], EMD, with their respective mathematical foundations [30]. The theory is taught in the classroom and the assessment is done by means of written examinations. The objective of the practical sessions is to contribute to the learning process of ANN of students at the undergraduate level, through useful applications for sustainable development. The student also knows the importance of signal processing techniques and how they can affect the process of network classification. The evaluation of the practical sessions are based on the ability of the students to translate the theory in a logical sequence, design the experiments, analyze the information, and finally, analyze the results obtained for the subsequent validation of the MLP. Students have to present an adequate interpretation of the application to obtain a certification of approval. When the students have the practical and theoretical knowledge, in the last month of the course, the students work in a team to develop a final project or senior project by suggesting topics regarding sustainable development such as health care, environmental solutions, power consumption, among others. Figure 2 depicts the process to achieve the senior project. The students propose the project by thinking on the impact of economics, environment and society. Some of this project can be found in [37]. 


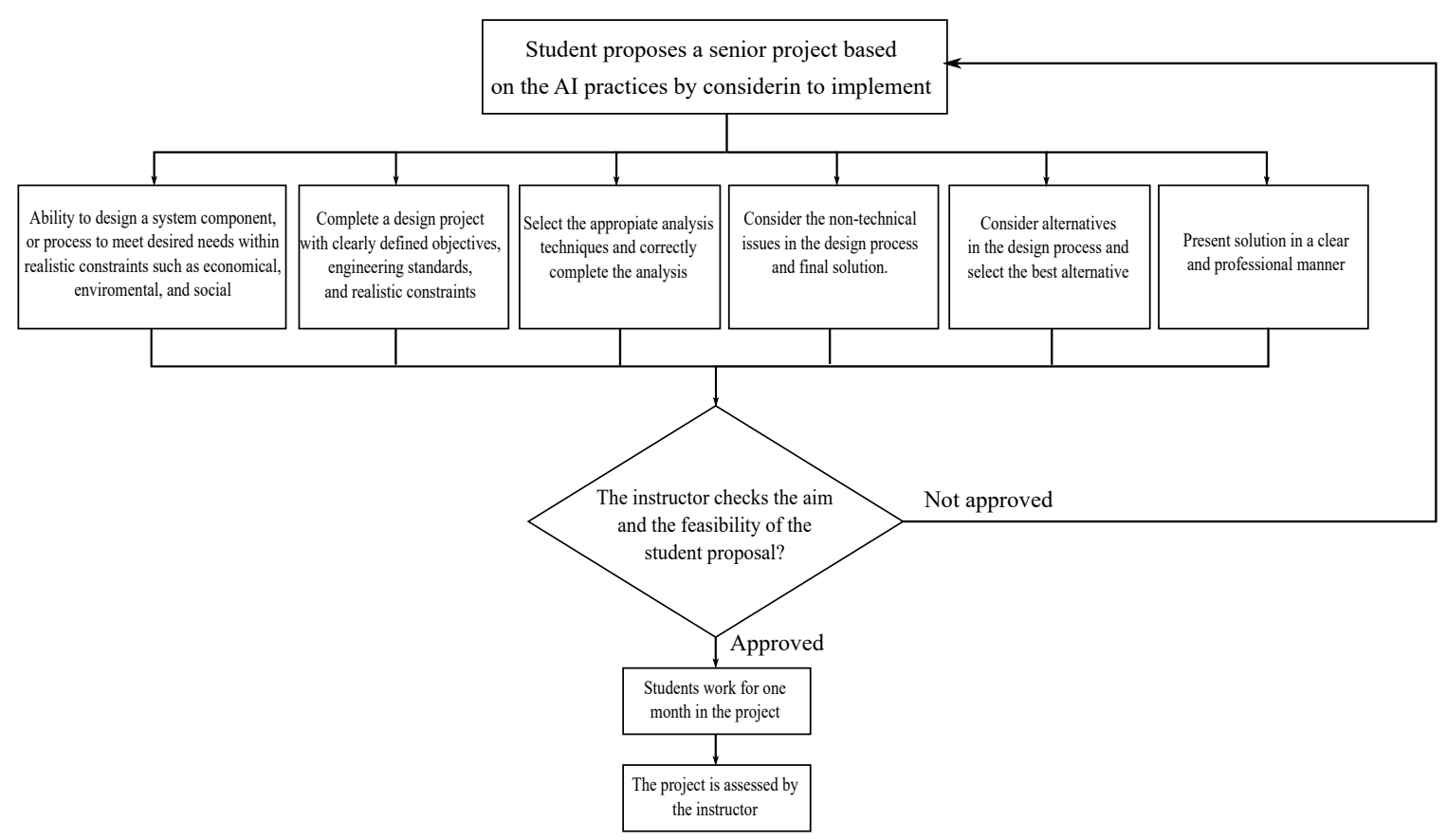

Figure 2. Flow chart of the process followed by the student to achieve the senior project.

\section{Practical Sessions}

The practical sessions starts with a basic introduction to the perceptron and later more competitive tasks such as MLP based data classification. The objectives of the practicals are given to the students before each session, so that they can develop the programming code. There are certain useful software for teaching AI techniques. For instance Phyton, C\#, C++, to mention a few. However, due to the time spent in the laboratory, the Matlab environment has been used since it has the functions to develop the workshop in the scholar period. Although python is more popular in research, this is done largely based on previously developed libraries like Keras or Tensorflow, where the fundamental concepts of the ANN are hidden. The instructor is responsible for guiding the students in the process of practical learning. The list and details of the practical sessions are provided below.

P1: Introduction to Matlab.

Objective: To become familiar with the Matlab platform, in order to provide the necessary concepts to perform the practicals.

Theory time: $1 \mathrm{~h}$.

Practical time: $2 \mathrm{~h}$.

For this activity, the teacher instructs the student the purpose of the screens with which the platform has. In order to later show him the management of vectors, matrices, and the basic operations that can be done with them. Then he goes on to the management of the basic control structures such as if, for, and while. The different methods to the graph are also taught and finally how to create and send to call a function or script.

P2: Create a simple perceptron.

Objective: To be able to practice the knowledge learned about the simple perceptron.

Theory time: $2 \mathrm{~h}$.

Practical time: $2 \mathrm{~h}$.

For this activity, it has been already ensured that they understand the concept, characteristics, advantages, disadvantages, and operation of the simple perceptron. Therefore the student is instructed to generate a.$m$ file that replicates the function of a simple perceptron, to classify between two different signals that are linearly separable. The requirement for this practical session is that students are not capable to use specific commands of the perceptron; they can 
only use basic instructions seen in past activity. Once it has been proven that the code has no syntax errors, they proceed to enter the inputs and keep a record of the number of iterations performed, the percentage of network classification and network characteristics. This last point is essential because several modifications to the are made so, the student identifies how each of the perceptron parameters can affect the classification process. Some tests that are carried out are: training the perceptron without an activating function, later placing the activation function, training using different learning rates, fixed and variable, different values for the step activation function, with bias, and without bias. In order to validate the results, the perceptron always has the same initial weights.

P3: Generate code for a multilayer perceptron.

Objective: To generate a code that performs the process of a multilayer perceptron, to complete the learning process of the theory previously seen.

Theory time: $4 \mathrm{~h}$.

Practical time: $3 \mathrm{~h}$.

For the next activity, the student generates a flow diagram explaining the operation of a multilayer perceptron, with a hidden layer. Then, they create a.$m$ file by taking the information of the flow diagram. For this code, the student is not able to make use of special command of ANN of Matlab, they do it using basic functions like addition, subtraction, multiplications, divisions, exponentials, etc., and basic control structures. The purpose of the previous knowledge helps to facilitate the upgrade between programming languages where the student is more aware to interchange the code no matter the environment.

P4: Function test of the multilayer perceptron.

Objective: To validate the multilayer perceptron code that they generated in the previous practical session.

Theory time: $1 \mathrm{~h}$.

Practical time: $2 \mathrm{~h}$.

In order to carry out this activity, students are provided with a database to achieve the classification process. In the case of biomedical students, they are provided of a database that corresponds to signals from patients with epilepsy and without epilepsy, taken with eyes closed and open. Mechatronics students were provided with a database showing signs of a milling process with broken cutters, worn and finally in good condition. Considering this database. They modify their created program to achieve the highest possible classification percentage.

P5: Functional test of the multilayer perceptron with the filtered signal using an FIR.

Objective: To understand how the learning of the network effects when the signal is processed using an FIR filter.

Theory time: $1 \mathrm{~h}$.

Practical time: $3 \mathrm{~h}$.

Because of the students have previously had contact with this type of techniques, and the purpose of the course is not the deep teaching of signal processing, the students are allowed to make use of Matlab tools for generating the filter. Because the mechatronics students use different databases, each group is provided with the characteristics of the filter to use. Once the filter is generated, the signals coming from the databases are filtered and introduced to the ANN, training and subsequent validation is proceed.

P6: Functional test of the multilayer perceptron with the signal using DWT.

Objective: To understand how the learning of the network influences when the signal is processed using a DWT.

Theory time: $1 \mathrm{~h}$.

Practical time: $3 \mathrm{~h}$.

Once the theory is understood, students proceed to modify the program of the network so that now the input receives the signals processed through DWT. Again they have to remember 
that as it is a different database, each group use different mother Wavelet and different levels of transformation.

P7: Multilayer perceptron operation test with a signal using EMD.

Objective: To understand how the learning of the network effects when the signal is processed using EMD.

Theory time: $1 \mathrm{~h}$.

Practical time: $3 \mathrm{~h}$.

Once again, the necessary changes has to be made to adapt the network to receive the signals processed using said transform. Up to this point, the student has sufficient arguments to determine if its effects or not the processing of the signals in the training of the network. At the same time, they have acquired the ability to modify each of the parameters such as learning rate, number of neurons, error, thresholds, initial weights, epoch, etc., in order to increase the percentage of classification of the network.

\section{Evaluation}

In this section, the program of the practical session and the method to evaluate both students and program is presented.

\subsection{Student Evaluation Rubric}

For the ANN course, the final grade could be from 0 to 100 Points, in this case. Table 1 shows the rubric to assess student performance, the ABET student outcomes consider the abilities involved in each part of the evaluation [4]. It was applied in a summative way with the students. On the right side, the lines show the concepts to be considered, which are theory, practice and senior project, while the columns show the rating that can be assigned according to certain parameters. In the rubric it is possible to observe that the final score is a result of the percentage assigned to the theory represent $50 \%$ of the total score, while the practice and the senior project are equivalent to $30 \%$ and $20 \%$, respectively. 
Table 1. Rubric for evaluating practical sessions based on Accreditation Board for Engineering and Technology Inc. (ABET) outcomes [4].

\begin{tabular}{|c|c|c|c|}
\hline \multirow{2}{*}{$\begin{array}{c}\text { Indicator } \\
\text { I } \\
\text { Identification }\end{array}$} & \multicolumn{3}{|c|}{ Criterion and Score } \\
\hline & $\begin{array}{l}\text { Includes the signed institutional cover: name of the student, name of the } \\
\text { activity, name of the professor and date of preparation. (Two points) }\end{array}$ & $\begin{array}{l}\text { It omits one identification datum. } \\
\text { (One point) }\end{array}$ & $\begin{array}{l}\text { Omits two or more identification } \\
\text { data or does not include } \\
\text { identification data. (Zero points) }\end{array}$ \\
\hline $\begin{array}{c}\text { II } \\
\text { Summary } \\
\text { ABET 3g }\end{array}$ & $\begin{array}{l}\text { Make a synthesis of the work with a minimum of } 100 \text { words and a } \\
\text { maximum of } 200 . \text { In addition, it incorporates three keywords that } \\
\text { represent the object of study. (Ten points) }\end{array}$ & $\begin{array}{l}\text { Make a synthesis of the work } \\
\text { with an extension of fewer than } \\
100 \text { words or not include the } \\
\text { three keywords (keywords) that } \\
\text { represent the object of study. } \\
\text { (5 Points) }\end{array}$ & $\begin{array}{l}\text { It does not make the summary. } \\
\text { (0 Points) }\end{array}$ \\
\hline $\begin{array}{c}\text { III } \\
\text { Introduction } \\
\text { ABET } 3 b \text { and } 3 g\end{array}$ & $\begin{array}{l}\text { It prepares an introduction in which it explains and justifies the } \\
\text { importance of the problem to be solved in a minimum of } 200 \text { words } \\
\text { and with a maximum of } 300 \text {. Referencing in the corresponding paragraph, } \\
\text { using the APA type (author, year). (Ten points) }\end{array}$ & $\begin{array}{l}\text { It prepares an introduction in } \\
\text { which it describes and justifies the } \\
\text { problem to solve, with less than } \\
200 \text { words. Either it does not cite } \\
\text { in the corresponding paragraph or } \\
\text { these references are not in the APA } \\
\text { format. (Five points) }\end{array}$ & $\begin{array}{l}\text { Does not elaborate the introduction. } \\
\text { (Zero points) }\end{array}$ \\
\hline $\begin{array}{l}\text { IV } \\
\text { Development } \\
\text { ABET 3a, 3b,3c, } \\
\text { 3e, 3g and 3k }\end{array}$ & $\begin{array}{l}\text { It incorporates a very complete } \\
\text { way the characteristics of the }\end{array} \begin{array}{l}\text { incorporates an incomplete } \\
\text { development of the program. Or it } \\
\text { developed program and the stages } \\
\text { does not show sufficient evidence } \\
\text { that comprise it. When applied, of an analytical, correct, reflexive, } \\
\text { perform a comparative analysis. systematic and coherent response } \\
\text { They present in an analytical, to respond to each of the criteria } \\
\text { correct, reflective, systematic and requested. (Twenty points) } \\
\text { coherent manner the way in which } \\
\text { the problem treated, as a clear } \\
\text { reflection of the understanding of } \\
\text { it. Use the criteria established } \\
\text { by the teacher for its realization. } \\
\text { (Thirty points) }\end{array}$ & $\begin{array}{l}\text { It incorporates a very weak analysis } \\
\text { of the problem to be addressed, } \\
\text { because it does not integrate a } \\
\text { coherent, reflective and analytical } \\
\text { response that reflects a systemic } \\
\text { thinking process to respond to } \\
\text { each of the established criteria. } \\
\text { (Ten points) }\end{array}$ & $\begin{array}{l}\text { No evidence of understanding } \\
\text { shows the problem or the way in } \\
\text { which it was resolved. Does not } \\
\text { use the criteria established by the } \\
\text { teacher. (Zero points) }\end{array}$ \\
\hline $\begin{array}{c}\text { V } \\
\text { Operation } \\
\text { of the program } \\
\text { ABET 3a, 3d, and 3e }\end{array}$ & $\begin{array}{l}\text { The program gives satisfactory results in each of the tests carried out. } \\
\text { (30 Points) }\end{array}$ & $\begin{array}{l}\text { The program provides satisfactory } \\
\text { results in at least } 80 \% \text { of the tests } \\
\text { carried out. (Twenty points) }\end{array}$ & $\begin{array}{l}\text { The program does not respond in } \\
\text { the expected way, or only in less } \\
\text { than } 80 \% \text { of the tests performed. } \\
\text { (Zero points) }\end{array}$ \\
\hline
\end{tabular}


Table 1. Cont.

\begin{tabular}{|c|c|c|c|}
\hline Indicator & \multicolumn{3}{|c|}{ Criterion and Score } \\
\hline $\begin{array}{l}\text { VI } \\
\text { Contribution } \\
\text { and recommendations } \\
\text { ABET a3, 3b, 3e, } \\
3 \mathrm{~g} \text { and } 3 \mathrm{k}\end{array}$ & $\begin{array}{l}\text { Locate relevant and meaningful data or opportunity areas on how to } \\
\text { solve or improve the proposed system, and how this can be applied } \\
\text { in other situations. For its development, the text contains a minimum } \\
\text { of } 150 \text { words and includes at least two updated sources of information. } \\
\text { (Ten points) }\end{array}$ & $\begin{array}{l}\text { It does not locate relevant data } \\
\text { or areas of opportunity that help } \\
\text { solve the problems presented } \\
\text { during the realization of the } \\
\text { activity, or how to apply it in } \\
\text { other situations. Either you do not } \\
\text { correctly reference the information } \\
\text { sources according to the APA } \\
\text { format, or you do not have at least } \\
\text { two current references. Or your } \\
\text { contributions include less than } 150 \\
\text { words. (Five points) }\end{array}$ & $\begin{array}{l}\text { It does not integrate } \\
\text { the contributions } \begin{array}{r}\text { and } \\
\text { recommendations. (Zero points) }\end{array}\end{array}$ \\
\hline \multicolumn{4}{|l|}{ VII } \\
\hline $\begin{array}{l}\text { Orthography } \\
\text { ABET } 3 g\end{array}$ & $\begin{array}{l}\text { It does not present orthographic errors and has the correct wording. } \\
\text { (Eight points) }\end{array}$ & $\begin{array}{l}\text { Presents } 1-3 \text { orthographic errors } \\
\text { and/or 1-3 writing errors. } \\
\text { (Five points) }\end{array}$ & $\begin{array}{l}\text { Presents four or more orthographic } \\
\text { errors and/or four or more writing } \\
\text { errors. (Zero points) }\end{array}$ \\
\hline
\end{tabular}




\subsection{Program Evaluation Rubric}

According to the theories of Vigotsky, particularly human learning is an essentially interactive process. In which in the case of education the teacher is an essential part of the scaffolding to build knowledge [6] it is the reason why students were asked to evaluate to the teacher, to know how much the latter influenced the process of learning and the fulfillment of the expectations of the students, a survey designed by the experts in education science was applied at the end of the course. The survey consisted of 25 questions that focus on six different areas, which are as follows:

A1: Course planning

A2: Strategies, methods, and techniques

A3: Evaluation

A4: Course management

A5: Information and communication technologies

A6: General satisfaction

The details of the applied survey can be found in [38]. This questionnaire was not mandatory to be fulfilled by the students. The quantitative analysis was applied to a total of 432 undergraduate students, divided as follows: 371 students in the specialty of Mechatronic engineering enrolled in the Advanced Control course; 41 students of the Biomedical engineering enrolled in the Intelligent Control course; and 20 students of Electronic engineering who took an intensive course on ANN. The course was taught by the same professor in the three institutions. Among the requirements requested in the reports of practices P4, P5, P6 and P7, was to include the characteristics of the MLP used, which include the number of layers used, number of neurons by layers, learning rate, maximum number of iterations. Within the results the student makes a statistical analysis that determines the percentage of recognition of the MLP for each type of signal. The results obtained in each practice was compared with the previous practice, in such a way that in practice P7 the student had a comparison of the percentages of classification when the signals are not processed and when they are processed with an FIR filter, EMD and DWT. The results obtained by the students for practices P4 to P7 are shown in Tables 2 and 3 . With these results, the student can determine how signal processing can influence the signal classification process. Of the 432 students enrolled in the course, $99.5 \%$ understood the influence of signal processing techniques before classification with ANN, where they showed changes in the classification percentages for the same signal depending on this previous processing. On the other hand, they showed the difficulty of making the same ANN configuration for the correct classification when the signals come from different physical phenomena.

Table 2. Results of mechatronic students obtained in practical sessions.

\begin{tabular}{ccccc}
\hline \multirow{2}{*}{ Signal Type } & \multicolumn{4}{c}{ Classification\% } \\
\cline { 2 - 5 } & P4 & P5 & P6 & P7 \\
\hline Broken insert & 70 & 94 & 87 & 91 \\
Insert in good condition & 74 & 97 & 89 & 92 \\
Wear broken & 68 & 93 & 86 & 94 \\
\hline
\end{tabular}

Table 3. Results of biomedical students obtained in practical sessions.

\begin{tabular}{ccccc}
\hline \multirow{2}{*}{ Signal Type } & \multicolumn{4}{c}{ Classification \% } \\
\cline { 2 - 5 } & P4 & P5 & P6 & P7 \\
\hline Epilepsy (eyes closed) & 63 & 91 & 95 & 96 \\
Epilepsy (eyes open) & 65 & 87 & 91 & 93 \\
Without epilepsy & 68 & 97 & 99 & 96 \\
\hline
\end{tabular}

The details of the results obtained from the evaluation of the students by a professor, and evaluation of the program by students are presented below. 


\subsection{Student Evaluation}

After the completion of the practices the students were evaluated using the rubric provided in Table 1. Figure 3 shows the average performance of students in each of the points evaluated by the rubric (I to VII) of practice P5 and practice P7. Here, it can be observed an increase in the scores, especially in the criteria IV, V and VI, which are the ones that can help us to evaluate the understanding of the MLP theory. In Figure 4 it can be seen an increase in the average score obtained by the students in each of the practices during the period 2015 to 2018.

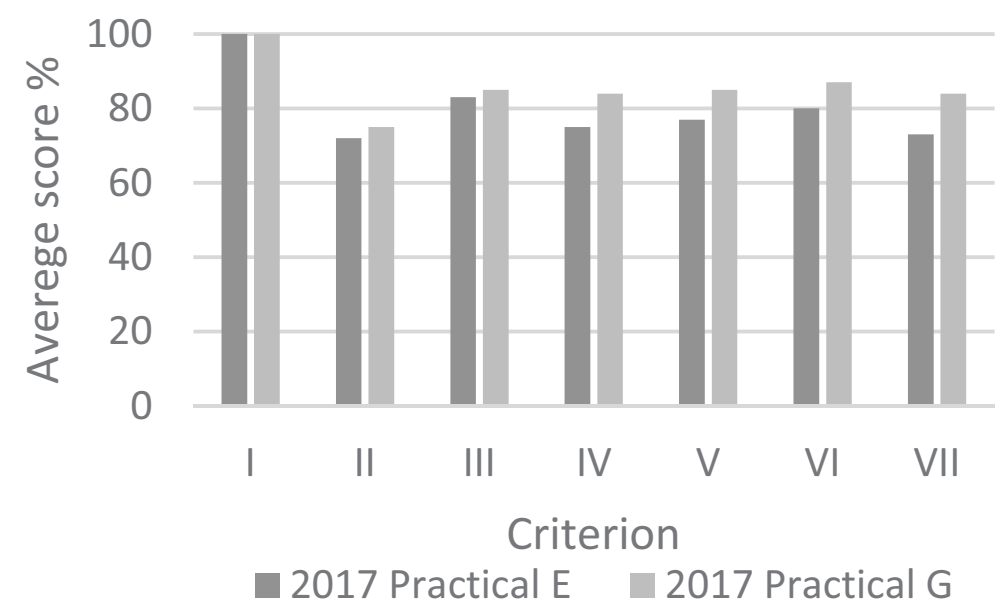

Figure 3. Comparative of the average score in practice P5 and P7 in 2017.

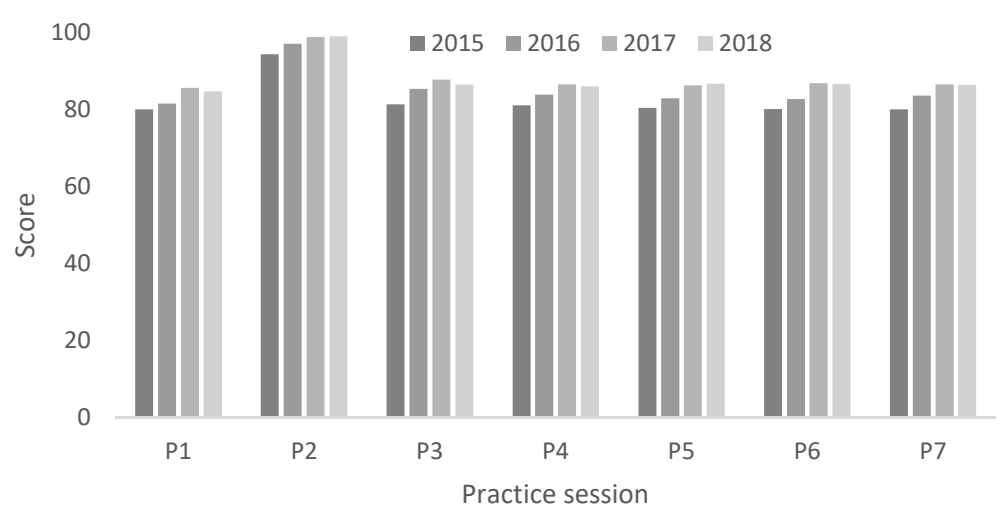

Figure 4. Annual average of practicals during different given courses.

In Figures 5 and 6 are represented the final grades according to each engineering major. It is shown that the final average scores increased while the standard deviation decreased. It is possible to observe that the average from all of the student outcomes has a positive score and the incremental trend during the time. In Figure 7 are depicted the average scores obtained from 2015 to 2018 by the evaluated groups. The practical and theoretical standard deviation analyzed for these cases decreased according to the evolution of the proposed method was applied. These observations show the effectiveness of ANN learning method for students from different disciplines, because although there are certain differences in the averages and standard deviation between groups, the trend is similar, where the average grades increase, while the differences between the maximum and minimum scores decrease.

Also its worth to mention that even though the majority of the students of biomedical engineering and mechatronic engineering were studying similar semesters and have similar ages, the way in which they solved the problems were not similar. It may be due to the fact that the characteristics of the educational system (technological system and University) varies among these majors. It can be noticed that the students of the Technological system (mechatronic) have a higher culture of evaluation 
towards the professors, when compared with the biomedical engineering students. The practicals which contain signal processing techniques were easier for biomedical students than mechatronics, electronics and communications, this is because these students had previously taken digital processing applied to biosignals.

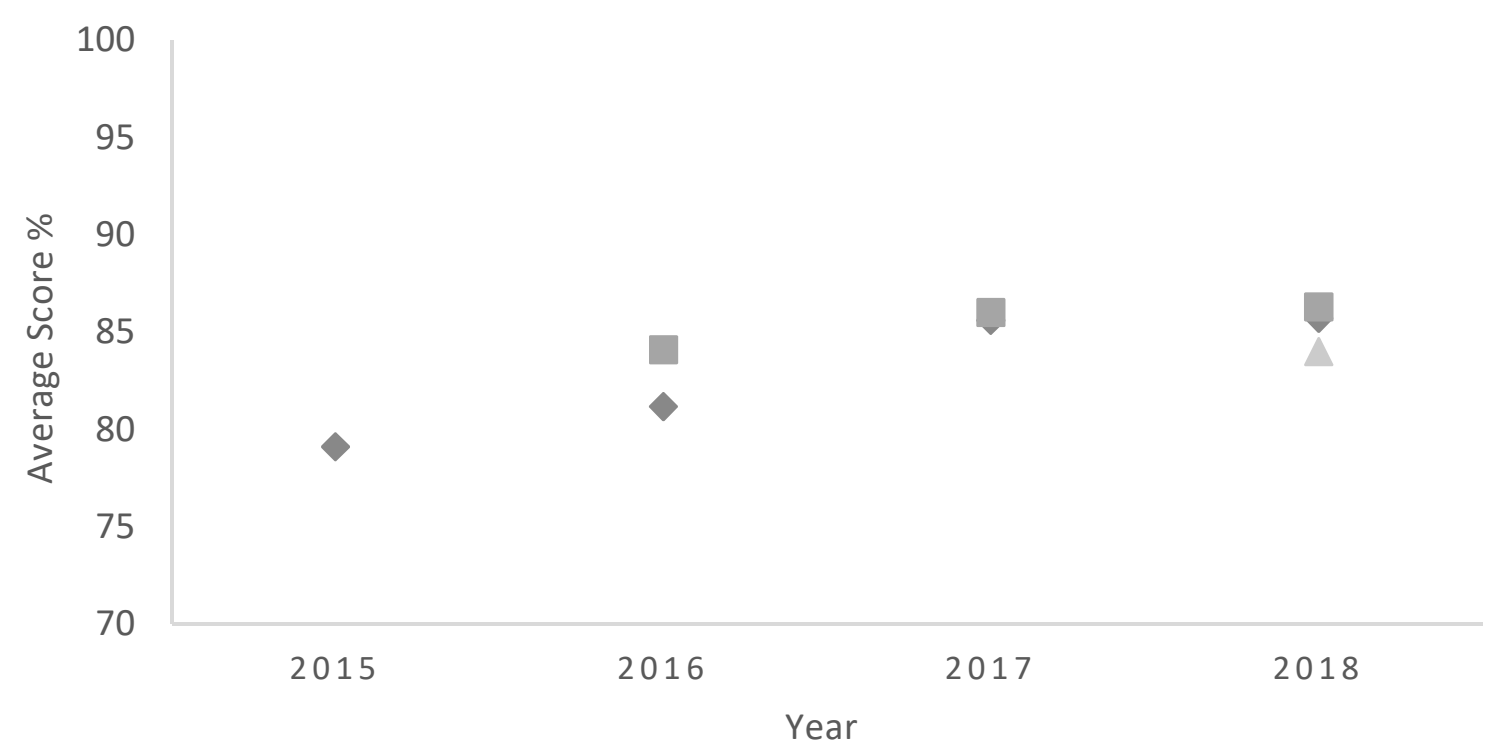

Figure 5. Performance of the students regarding the majors of mechatronics (M), biomedical (B), and electronics $(\mathrm{E})$.

\section{III $\triangle$ IV $\mathbb{X V} \mathbb{X V}$}

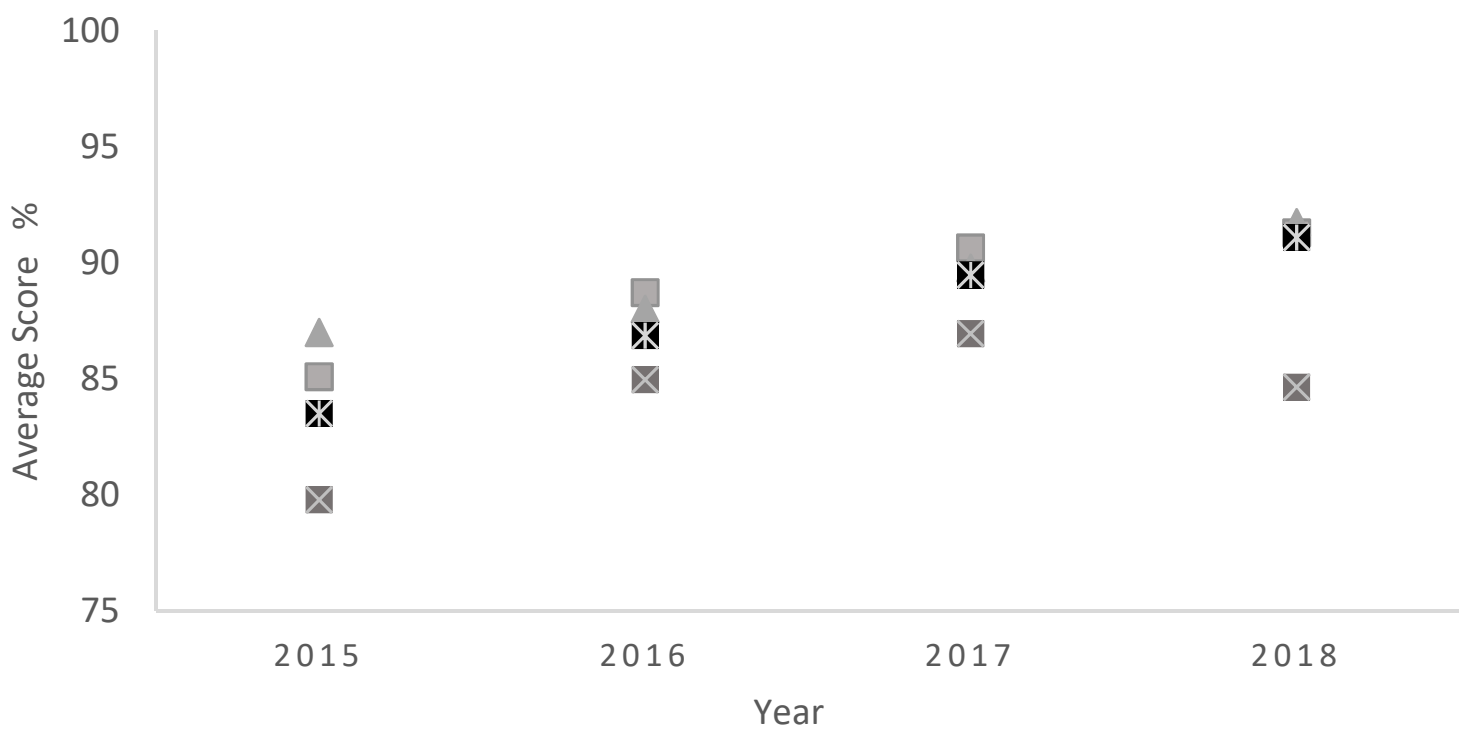

Figure 6. Annual average of students grades from the rubric. 


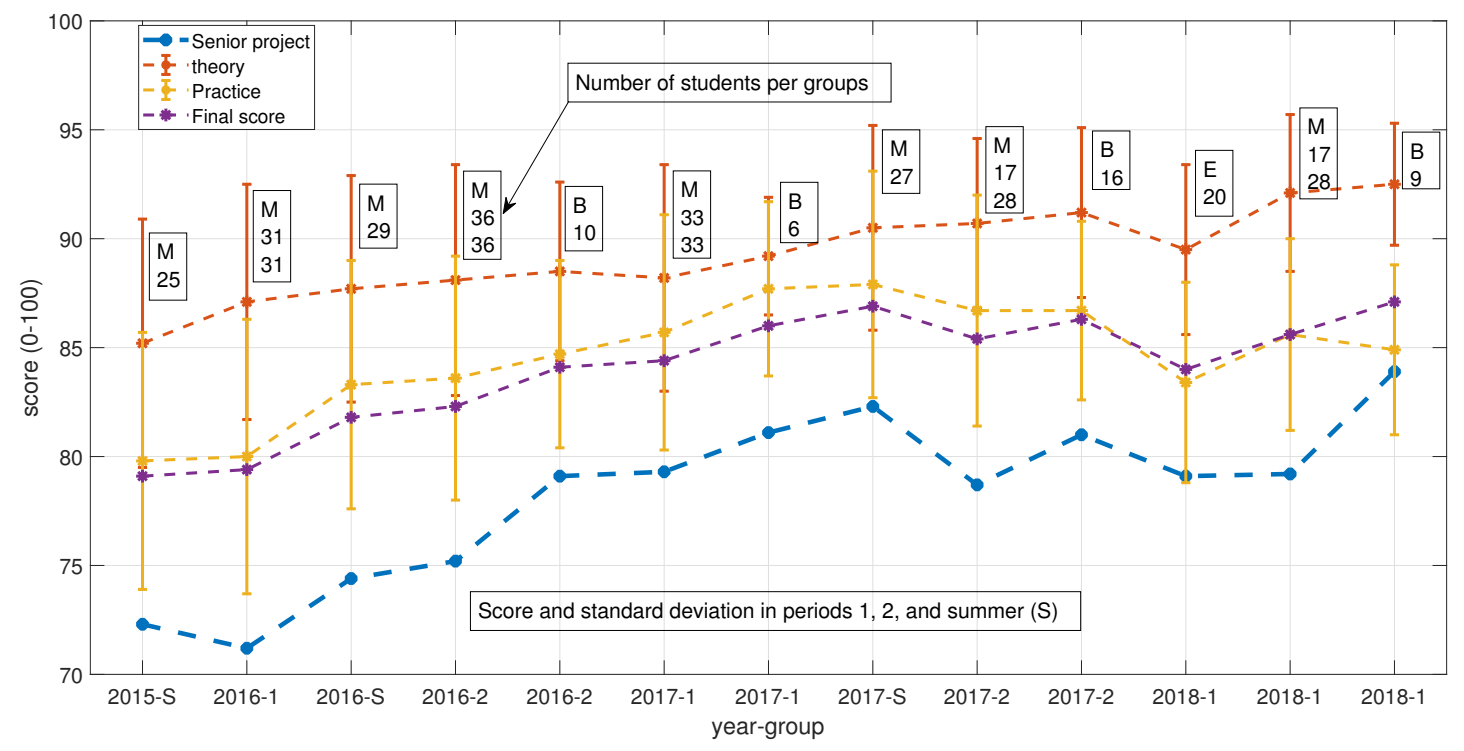

Figure 7. Average mark of the students enrolled in the course performance of the students regarding the majors of mechatronics (M), biomedical (B), and electronics (E).

\subsection{Program Evaluation}

The grades can corroborate if the proposed practical portfolio has a good design for teaching, however its worth to note that the environment has a significant influence during learning process $[11,12]$. From this point of view, the survey could be an appropriate and added way to obtain feedback [38]. The results obtained from the survey is resumed in Table 4 according to Likert scale [39]. Although the results were satisfactory, it is easy to determine that the answers may be affected by the subjectivity of the student and by the times in which the survey is applied.

Table 4. Annual average of the course evaluation and average per carrer regarding the majors of mechatronics (M), biomedical (B), and electronics (E).

\begin{tabular}{cccccccc}
\hline Area & $\mathbf{2 0 1 5}$ & $\mathbf{2 0 1 6}$ & $\mathbf{2 0 1 7}$ & $\mathbf{2 0 1 8}$ & $\mathbf{M}$ & $\mathbf{B}$ & $\mathbf{E}$ \\
\hline A1 & 4.60 & 4.50 & 4.62 & 4.66 & 4.48 & 4.70 & 4.50 \\
A2 & 4.40 & 4.44 & 4.42 & 4.70 & 4.38 & 4.50 & 4.70 \\
A3 & 4.50 & 4.54 & 4.60 & 4.66 & 4.50 & 4.62 & 4.70 \\
A4 & 4.50 & 4.55 & 4.58 & 4.53 & 4.53 & 4.52 & 4.60 \\
A5 & 4.50 & 4.60 & 4.54 & 4.66 & 4.57 & 4.55 & 4.70 \\
A6 & 4.30 & 4.50 & 4.48 & 4.56 & 4.49 & 4.50 & 4.70 \\
\hline
\end{tabular}

The opinions of the students with respect to the strategies and methodology used varied little in the years 2015 to 2017. Nevertheless, it increased considerably in 2018. But, it could have been due to the improvement in the strategies of the course or to the fact that it was a professor other than the Institution who taught the course, which made them perceive a change in the methods of learning or way of working with the teacher. The professor who taught the course had previous interaction with the students of Biomedical engineering because with him they studied previous subjects. This situation did not happen with the students of Mechatronics and Electronics and Communications. However, it is considered that this did not influence the evaluation because of the evaluations of the Biomedical and Mechatronics students are very similar, and higher results were obtained with the students of Electronics and Communications. Regarding the mode of the course, which could be semester, summer or intensive course; it can be seen that the highest grades have been registered in the summer mode (2017-S) and the intensive course 2018, which was given during the inter semester period. However, it is 
not possible to determine if this is because the stress of the students is less since they are concentrated on one subject. The groups in which the course was applied had a maximum of 36 students and a minimum of 6 . However, it cannot be concluded that this could have been a significant factor that influences the perception of the students, the course, evaluation, strategies, methods and techniques used; or if they was more influenced by the type of institution.

\section{Discussion}

In this paper, it has been demonstrated that does not matter the major, the method work for different careers proposed. Regarding the annual analysis, the general results of the survey were 4.5 in years 2015 and 2016; 4.54 in 2017; and 4.63 in 2018. These results show that the grades obtained have increased although it has been gradual. The same growing happens with the grades during the analysis, from this, it is possible to say that the perception from the students about the practical sessions are related to their own grades. It is according to the mode of the course, it be seen that the intensive course obtained the highest general average (4.65), followed by the summer course with an average of 4.59 , and finally, the course taught semiannually with an average from 4.52 . However, it is not possible to determine which was the factor that most influences the result.

The proposed practical sessions were applied to a total of 347 students of three public institutions of higher level with students of three different specialties, 295 students of Engineering in Mechatronics, 32 students of biomedical Engineering, and 20 students of Engineering in electronics and communications. The practicals were applied in three different modes, a semester course of $4 \mathrm{~h}$ per week, a summer course of $3 \mathrm{~h}$ a day and an intensive course of $30 \mathrm{~h}$ divided into $6 \mathrm{~h}$ a day. $81.84 \%$ of the students answered a survey of 25 questions whose maximum score is 5 and the minimum is 1 . The general averages obtained for each item are 1. Course planning 4.6; 2 . Evaluation 4.48; 3. Strategies, methods and techniques 4.57; 4 . Management of the course $4.54 ; 5$. Information and communication technologies 4.58; and 6. General satisfaction 4.52. From the analysis of the data obtained from 2015 to 2018 , the following general averages were obtained: mechatronics 4.49 , biomedical 4.57 and electronics and communications 4.65 .

\section{Conclusions}

This work presented a methodology that can be adapted to certain academic programs. It does not matter the frequency of the subject. For instance, it can be implemented in a summer or semestral period. Besides, the orientation of the senior project is to solve issues of the society and industry sustainably.

In the biomedical, mechatronics and electronics majors, students give solutions regarding health, mainly in diagnostic of illnesses, diagnostic of failures in machinery and signal processing, respectively.

By this methodology, AI topics can be covered by following the constructivism approach, that permits the students to increase their skills by starting from the previous knowledge.

The use of Matlab in this course permits the students to translate the codes to Phyton, C\#, and C++, to mention a few. Moreover, the code can be embedded in certain starter kits of hardware.

According to the statistical analysis carried out with the data obtained during the four years of application of the proposed methodology, there is an increase in the average of the grades obtained by the students, as well as a reduction in the standard deviation, which indicates that learning process and ABET skills were more homogeneous.

The rubric presented has been continuously improved in each course, so it is considered appropriate and accepted by students according to the survey conducted. In addition, it meets the requirements established by each of the accrediting organizations such as CACEI, CIIES, and ABET.

Finally there are certain web resources that were obtained in this research that other schools can adapt in their institutions. 
Author Contributions: Conceptualization, G.M.-V. and J.R.-R.; methodology, G.M.-V.; software, G.M.-V.; validation, G.M.-V., E.E.C.-M., and J.R.-R.; formal analysis, G.M.-V.; investigation and visualization, G.M.-V., G.H.-R. and J.R.-R.; data curation, G.M.-V., G.H.-R., and J.R.-R.; writing-original draft preparation; writing-original draft, review, and editing, all the authors.

Funding: This research was funded by the "Consejo Nacional de Ciencia y Tecnología (CONACYT)" and "Programa para el Desarrollo Profesional Docente, para el Tipo Superior (PRODEP)".

Acknowledgments: The authors of this work are especially grateful to the Faculty of Engineering of the Autonomous University of Querétaro for their support in carrying out this research, as well as to Mariano Garduño-Aparicio, Suresh Thenozhi, César Ortiz-Echeverri and Carmen Sosa-Garza for their contribution to this work.

Conflicts of Interest: The authors declare no conflict of interest.

\section{References}

1. Gao, H.; Cheng, B.; Wang, J.; Li, K.; Zhao, J.; Li, D. Object classification using CNN-based fusion of vision and LIDAR in autonomous vehicle environment. IEEE Trans. Ind. Inform. 2018, 14, 4224-4231. [CrossRef]

2. Xie, G.; Gao, H.; Qian, L.; Huang, B.; Li, K.; Wang, J. Vehicle trajectory prediction by integrating physics-and maneuver-based approaches using interactive multiple models. IEEE Trans. Ind. Electron. 2017, 65, 5999-6008. [CrossRef]

3. An, L.; Zhang, X.; Gao, H.; Liu, Y. Semantic segmentation-aided visual odometry for urban autonomous driving. Int. J. Adv. Robot. Syst. 2017, 14, 1729881417735667. [CrossRef]

4. Criteria for Accrediting Engineering Programs Document Number E001, Accreditation Commission and ABET. Available online: https://www.abet.org/wp-content/uploads/2015/05/E001-15-16-EAC-Criteria03-10-15.pdf (accessed on 30 May 2019).

5. Piaget, J. The Psychology of Intelligence; Littlefield: Totowa, NJ, USA, 1972.

6. Vigotsky, L.S. Los Procesos Psicológicos Superiores. Available online: https://saberespsi.files. wordpress.com/2016/09/vygostki-el-desarrollo-de-los-procesos-psicolc3b3gicos-superiores.pdf (accessed on 23 August 2019). .

7. Dogmus, Z.; Erdem, E.; Patoglu, V. ReAct!: An interactive educational tool for AI planning for robotics. IEEE Trans. Educ. 2014, 58, 15-24. [CrossRef]

8. Du Boulay, B. Artificial intelligence as an effective classroom assistant. IEEE Intell. Syst. 2016, 31, 76-81. [CrossRef]

9. Tan, D.P.; Ji, S.M.; Jin, M.S. Intelligent computer-aided instruction modeling and a method to optimize study strategies for parallel robot instruction. IEEE Trans. Educ. 2012, 56, 268-273. [CrossRef]

10. Jang, S.J. The effects of integrating technology, observation and writing into a teacher education method course. Comput. Educ. 2008, 50, 853-865. [CrossRef]

11. John-Steiner, V.; Mahn, H. Sociocultural approaches to learning and development: A Vygotskian framework. Educ. Psychol. 1996, 31, 191-206. [CrossRef]

12. Lourenço, O. Piaget and Vygotsky: Many resemblances, and a crucial difference. New Ideas Psychol. 2012, 30, 281-295. [CrossRef]

13. Blake, B.; Pope, T. Developmental Psychology: Incorporating Piaget's and Vygotsky's Theories in Classrooms. 2015. Available online: https:/ / pdfs.semanticscholar.org/6c7b/9a7b4988df15c68a14434a5f162bef984723.pdf (accessed on 23 August 2019).

14. Kalina, C.; Powell, K. Cognitive and social constructivism: Developing tools for an effective classroom. Education 2009, 130, 241-250.

15. Lamont, L.; Chaar, L.; Toms, C. Using interactive problem-solving techniques to enhance control systems education for non English-speakers. Eur. J. Eng. Educ. 2010, 35, 99-108. [CrossRef]

16. Lee, W.; Conklin, N.B. Improvement of student learning experience via an interdisciplinary undergraduate research project with top-down design and bottom-up implementation. In Proceedings of the 2017 IEEE Integrated STEM Education Conference (ISEC), Princeton, NJ, USA, 11 March 2017; pp. 49-51.

17. Lundy, M.; Aceros, J. A community-based, interdisciplinary rehabilitation engineering course. In Proceedings of the 2016 38th Annual International Conference of the IEEE Engineering in Medicine and Biology Society (EMBC), Orlando, FL, USA, 16-20 August 2016; pp. 3006-3009. 
18. Weissbach, R.S.; Pflueger, R.C. Collaborating with Writing Centers on Interdisciplinary Peer Tutor Training to Improve Writing Support for Engineering Students. IEEE Trans. Prof. Commun. 2018, 61, 206-220. [CrossRef]

19. Wulfken, B.; Müller, E. How to improve employee education-Methodological approach to structure specialist and interdisciplinary requirements. In Proceedings of the 2017 IEEE International Conference on Industrial Engineering and Engineering Management (IEEM), Singapore, 10-13 December 2017; pp. 130-134.

20. Zhang, Z. Autonomous mental development: A new interdisciplinary transactions for natural and artificial intelligence. IEEE Trans. Auton. Ment. Dev. 2016, 1, 1-11. [CrossRef]

21. Van Til, R.P.; Sengupta, S.; Dessert, P.; Srodawa, R.; Wagner, C. An interdisciplinary laboratory for teaching manufacturing and artificial intelligence. In Proceedings of the Frontiers in Education 1997 27th Annual Conference. Teaching and Learning in an Era of Change, Pittsburgh, PA, USA, 5-8 November 1997; Volume 3.

22. Venayagamoorthy, G.K.K. A successful interdisciplinary course on coputational intelligence. IEEE Comput. Intell. Mag. 2009, 4, 14-23. [CrossRef]

23. Gertrudes, J.; Maltarollo, V.G.; Silva, R.; Oliveira, P.R.; Honorio, K.M.; Da Silva, A. Machine learning techniques and drug design. Curr. Med. Chem. 2012, 19, 4289-4297. [CrossRef] [PubMed]

24. Martínez-Prado, M.A.; Rodríguez-Reséndiz, J.; Gómez-Loenzo, R.A.; Camarillo-Gómez, K.A.; Herrera-Ruiz, G. Short informative title: Towards a new tendency in embedded systems in mechatronics for the engineering curricula. Comput. Appl. Eng. Educ. 2019, 27, 603-614. [CrossRef]

25. Garduño-Aparicio, M.; Rodríguez-Reséndiz, J.; Macias-Bobadilla, G.; Thenozhi, S. A multidisciplinary industrial robot approach for teaching mechatronics-related courses. IEEE Trans. Educ. 2017, 61, 55-62. [CrossRef]

26. Abidi, S.M.R.; Hussain, M.; Xu, Y.; Zhang, W. Prediction of Confusion Attempting Algebra Homework in an Intelligent Tutoring System through Machine Learning Techniques for Educational Sustainable Development. Sustainability 2019, 11, 105. [CrossRef]

27. Wang, W.; Zhang, G.; Yang, L.; Balaji, V.; Elamaran, V.; Arunkumar, N. Revisiting signal processing with spectrogram analysis on EEG, ECG and speech signals. Future Gener. Comput. Syst. 2019, 98, 227-232. [CrossRef]

28. Proakis, J.G.; Manolakis, D.S.G.; Santalla del Río, V.; Castro, A.; Luis, J. Tratamiento Digital de Señales. Available online: https://es.scribd.com/document/268752766/Tratamiento-Digital-de-Senales-Proakis (accessed on 23 August 2019).

29. Mallat, S. A Wavelet Tour of Signal Processing; Elsevier: Amsterdam, The Netherlands, 1999.

30. Huang, N.E.; Shen, Z.; Long, S.R.; Wu, M.C.; Shih, H.H.; Zheng, Q.; Yen, N.C.; Tung, C.C.; Liu, H.H. The empirical mode decomposition and the Hilbert spectrum for nonlinear and non-stationary time series analysis. Proc. R. Soc. Lond. Ser. A Math. Phys. Eng. Sci. 1998, 454, 903-995. [CrossRef]

31. Russell, S.; Norvig, P.; Rodríguez, J. Inteligencia Artificial: Un Enfoque Moderno. Available online: https:/ / luismejias21.files.wordpress.com/2017/09/inteligencia-artificial-un-enfoque-modernostuart-j-russell.pdf (accessed on 23 Aug 2019).

32. Cruz, P.; Herrera, A. Inteligencia Artificial Con Aplicaciones a La Ingeniería. Available online: https://lelinopontes.files.wordpress.com/2014/09/inteligencia-artificial-con-aplicaciones-a-laingenierc3ada.pdf (accessed on 23 August 2019).

33. Hornik, K.; Stinchcombe, M.; White, H. Multilayer feedforward networks are universal approximators. Neural Netw. 1989, 2, 359-366. [CrossRef]

34. Cui, C.; Wang, D. High dimensional data regression using Lasso model and neural networks with random weights. Inf. Sci. 2016, 372, 505-517. [CrossRef]

35. Yao, X. Evolutionary artificial neural networks. Int. J. Neural Syst. 1993, 4, 203-222. [CrossRef]

36. Xin, Y. A review of evolutionary artificial neural networks. Int. J. Intell. Syst. 1993, 8, 539-565.

37. Senior Project of Artificial Intelligence Subject Oriented to Sustainable Development. Available online: http:/ / www.juvenal.mx./MDPI (accessed on 30 July 2019). 
38. Survey Applied to the Undergraduates Students to Measure the Performance of the Instructor. Available online: http:/ / www.juvenal.mx./ToE (accessed on 7 August 2019).

39. Gliem, J.A.; Gliem, R.R. Calculating, interpreting, and reporting Cronbach's alpha reliability coefficient for Likert-type scales. In Proceedings of the Midwest Research-to-Practice Conference in Adult, Continuing and Community Education, Columbus, OH, USA, 8-10 October 2003.

(C) 2019 by the authors. Licensee MDPI, Basel, Switzerland. This article is an open access article distributed under the terms and conditions of the Creative Commons Attribution (CC BY) license (http:/ / creativecommons.org/licenses/by/4.0/). 